\title{
Simulation and skills training in mitral valve surgery
}

\author{
David L. Joyce, MD, ${ }^{\mathrm{a}, \mathrm{b}}$ Tanvir S. Dhillon, BS, ${ }^{\mathrm{c}}$ Anthony D. Caffarelli, MD, ${ }^{\mathrm{a}, \mathrm{b}}$ Daniel D. Joyce, BA, ${ }^{\mathrm{d}}$ \\ Dimitrios N. Tsirigotis, MD, PhD, ${ }^{\mathrm{e}}$ Thomas A. Burdon, MD, ${ }^{\mathrm{a}, \mathrm{b}}$ and James I. Fann, MD ${ }^{\mathrm{a}, \mathrm{b}}$
}

Objective: Limited exposure and visualization and technical complexity have affected resident training in mitral valve surgery. We propose simulation-based learning to improve skill acquisition in mitral valve surgery.

\begin{abstract}
Methods: After reviewing instructional video recordings of mitral annuloplasty in porcine and plastic models, 11 residents (6 integrated and 5 traditional) performed porcine model mitral annuloplasty. Video-recorded performance was reviewed by attending surgeon providing audio formative feedback superimposed on video recordings; recordings were returned to residents for review. After 3-week practice with plastic model, residents repeated porcine model mitral annuloplasty. Performance assessments initially (prefeedback) and at 3 weeks (postfeedback) were based on review of video recordings on 5-point rating scale (5, good; 3 , average; 1 , poor) of 11 components. Ratings were averaged for composite score.
\end{abstract}

Results: Time to completion improved from mean $31 \pm 9$ minutes to $25 \pm 6$ minutes after 3 -week practice $(P=.03)$. At 3 weeks, improvement in technical components was achieved by all residents, with prefeedback scores varying from $2.4 \pm 0.6$ for needle angles to $3.0 \pm 0.5$ for depth of bites and postfeedback scores of $3.1 \pm$ 0.8 for tissue handling to $3.6 \pm 0.8$ for suture management and tension $(P \leq .001)$. Interrater reliability was greater than 0.8. In this sample, composite scores of first-year integrated and traditional residents were lower than those of senior level residents; comparatively, third-year integrated residents demonstrated good technical proficiency.

Conclusions: Simulation-based learning with formative feedback results in overall improved performance of simulated mitral annuloplasty. In complex surgical procedures, simulation may provide necessary early graduated training and practice. Importantly, a "passing" grade can be established for proficiency-based advancement. (J Thorac Cardiovasc Surg 2011;141:107-12)

Mitral valve surgery represents a technically challenging surgical procedure to perform and to teach. For instance, in mitral regurgitation, improved survival is associated with mitral valve repair relative to replacement, ${ }^{1,2}$ but choosing the right approach requires not only technical expertise but both extensive knowledge of anatomy and pathophysiology and sound intraoperative judgment. Current Accreditation Council for Graduate Medical Education requirements ${ }^{3}$ do not mandate that a specific

From Stanford University, ${ }^{\mathrm{a}}$ Stanford, Calif; VA Palo Alto Health Care System, ${ }^{\mathrm{b}}$ Palo Alto, Calif; University of California, ${ }^{\mathrm{c}}$ San Diego, San Diego, Calif; New York University, ${ }^{\mathrm{d}}$ New York, NY; and Yale University School of Medicine, ${ }^{\mathrm{e}}$ New Haven, Conn.

Supported by the simulation grant from the Thoracic Surgery Foundation for Research and Education and grants from the Sorin Group, Medtronic, Inc, and the Center for Immersive and Simulation-Based Learning at Stanford University.

Disclosures: Authors have nothing to disclose with regard to commercial support.

Read at the 36th Annual Meeting of The Western Thoracic Surgical Association, Ojai, Calif, June 23-26, 2010.

Received for publication June 7, 2010; revisions received July 27, 2010; accepted for publication Aug 24, 2010; available ahead of print Nov 12, 2010.

Address for reprints: James I. Fann, MD, Department of Cardiothoracic Surgery, Stanford University, 300 Pasteur Dr, Stanford, CA 94305 (E-mail: jfann@ stanford.edu).

0022-5223/\$0.00

Published by Elsevier Inc. on behalf of The American Association for Thoracic Surgery

doi:10.1016/j.jtcvs.2010.08.059 number of mitral valve procedures be performed by the resident during training; rather, there is a requirement of 50 valve procedures, with no distinction between aortic and mitral valve surgery. Additionally, there may be a limited volume of mitral valve surgery at a given institution, further affecting the training experience.

Simulation-based learning has been proposed as an approach to enhance resident performance in cardiothoracic surgery. ${ }^{4-10}$ We propose that resident experience in mitral valve surgery can be augmented by the introduction of such training during residency. By evaluating technical components of mitral valve annuloplasty that define competency and helping residents achieve these standards through simulation, we hope to facilitate skills training and acquisition in mitral valve surgery.

\section{MATERIALS AND METHODS}

At a single institution during the transition from a traditional to an integrated cardiothoracic surgical residency training program, 11 residents ( 5 previously trained in general surgery [traditional program] and 6 in the 6-year integrated program) participated in this study at the beginning of the academic year. Residents in years 1 to 3 of the integrated program (R1-R3) and those in year 1 of the traditional program (T1) had not previously performed mitral valve surgery in the clinical setting. With the exception of a single R3 resident who had performed a single cardiac surgical case, none of the integrated residents (R1-R3) had performed any cardiac surgical case as surgeon rather than assistant. Neither of the T1 residents 
had performed any cardiac surgical cases as surgeon, because they had just completed general surgical residency. Residents in years 2 and 3 of the traditional program ( $\mathrm{T} 2$ and $\mathrm{T} 3$ ) had performed mitral valve procedures before this simulation exercise. The $2 \mathrm{~T} 2$ residents had performed 19 and 20 cases. The T3 resident had performed nearly 240 cases as surgeon. Approval to conduct this study was obtained from the institutional review board.

\section{Porcine Heart Model}

Explanted porcine hearts were placed in the container (Wet-Lab, Ltd, Kenilworth, Warwick, UK) and situated to present the left atrium and mitral annular plane at an angle mimicking that in the operating room. The left atrium was opened, and stay sutures were placed the expose the mitral valve and annulus in an anatomically correct configuration, with visibility of the anterior annulus, posterior annulus, and commissures (Figure 1). The depth of the annulus relative to the top of the container was approximately $6 \mathrm{~cm}$. The exposure in this porcine model provides the trainee with an opportunity for assessment of the valve leaflets, annulus, and subvalvular structures.

\section{Plastic Mitral Valve Model}

The plastic mitral valve model is a silicone-based cylinder with an opening of $7 \mathrm{~cm}$ in diameter and a depth of $5.5 \mathrm{~cm}$ (Chamberlain Group, Great Barrington, Mass; Figure 2). The commissure-to-commissure distance is $35 \mathrm{~mm}$, and the anteroposterior dimension measures $26 \mathrm{~mm}$. The model is moderately pliable, which permits some degree of traction and relaxation during suture placement. The cylindrical configuration and the relatively flat plane of the annulus require awareness of needle angles (ie, mounting the needle on the needle driver) for optimal placement of the sutures. The annulus provides reasonable tactile response to suture placement, which permits assessment of the depth of bites, suture advance, and spacing between sutures.

\section{Protocol}

All residents reviewed instructional video recordings demonstrating how to perform a mitral annuloplasty with both the porcine model and the plastic mitral model. A few days later, each resident performed a mitral annuloplasty with the porcine model (prefeedback). Standard surgical instruments were used. Sutures were 2-0 Ethibond with RB-1 needles (Ethicon, Inc, Somerville, NJ), and the annuloplasty rings were either Sorin Annuloflow or Sorin Annuloflex (Sorin Group USA, Arvada, Colo). The procedure was timed and video recorded with a head-mounted camera and 2 peripheral cameras. All data were stripped of identifying information and stored on a computer hard drive. Video recordings were submitted to a senior faculty surgeon (J.I.F.) blinded to the identity of the resident. Formative feedback was given as a narrated video recording (audio recording superimposed on the video recording) and returned to each resident for review within 1 week. Residents were given 2 additional weeks to practice the exercise on the plastic mitral model after reviewing the video recording with feedback. Instruments, sutures, and annuloplasty ring were provided. Home practice times were recorded. Three weeks after the initial simulation session, the residents repeated mitral annuloplasty with the porcine model (postfeedback); these procedures were video recorded. Resident performance was evaluated on the basis of review of the video recordings in a blinded fashion by 2 surgeons (J.I.F., T.A.B.) familiar with the use of the rating scale.

\section{Performance Assessment}

Resident performance was assessed according to a 5-point rating scale modified from the Objective Structured Assessment of Technical Skills described by Reznick and colleagues ${ }^{11,12}$ (Table 1). The 11 components of the procedure assessed included identification of anterior annulus, identification of posterior annulus, needle angles, needle removal from annulus, tissue handling, depth of bite, suture advance along annulus, spacing between sutures, situating mitral ring, knot-tying, and suture management and tension. A composite score averaging the scores of the 11 components was calculated for each resident.
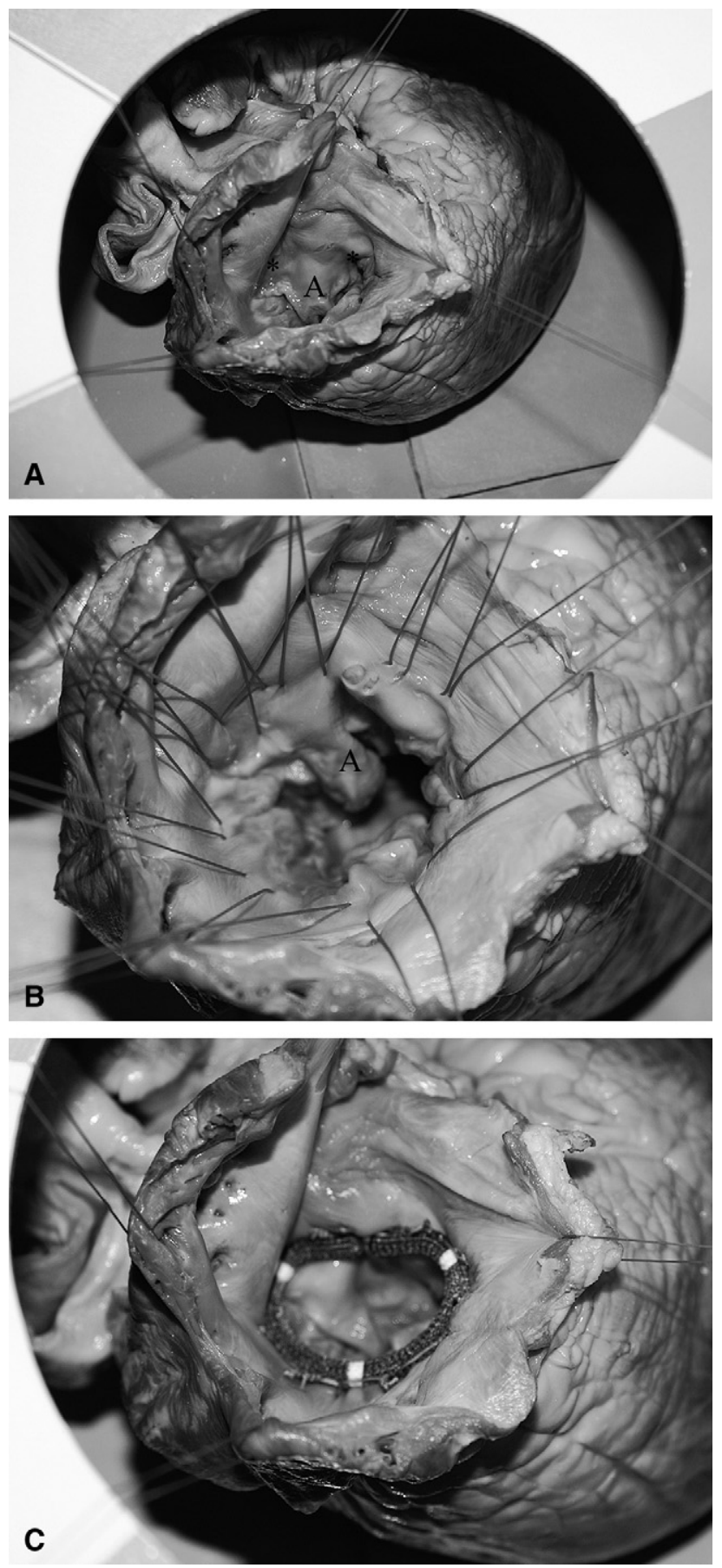

FIGURE 1. Porcine mitral annuloplasty simulation exercise was recorded with head camera and 2 peripheral cameras. Exposure of mitral valve in the container (A), after annular suture placement (B), and after seating annuloplasty ring (C). A, Anterior leaflet. Asterisks indicate trigones.

\section{Statistical Analysis}

Data are presented as mean $\pm \mathrm{SD}$. Time to completion data were analyzed with a paired $t$ test that compared prefeedback times with postfeedback times. Components of the rating scale (prefeedback and postfeedback) were analyzed with paired $t$ tests. To assess interrater reliability when scoring the participants, we used the statistic Savr described 

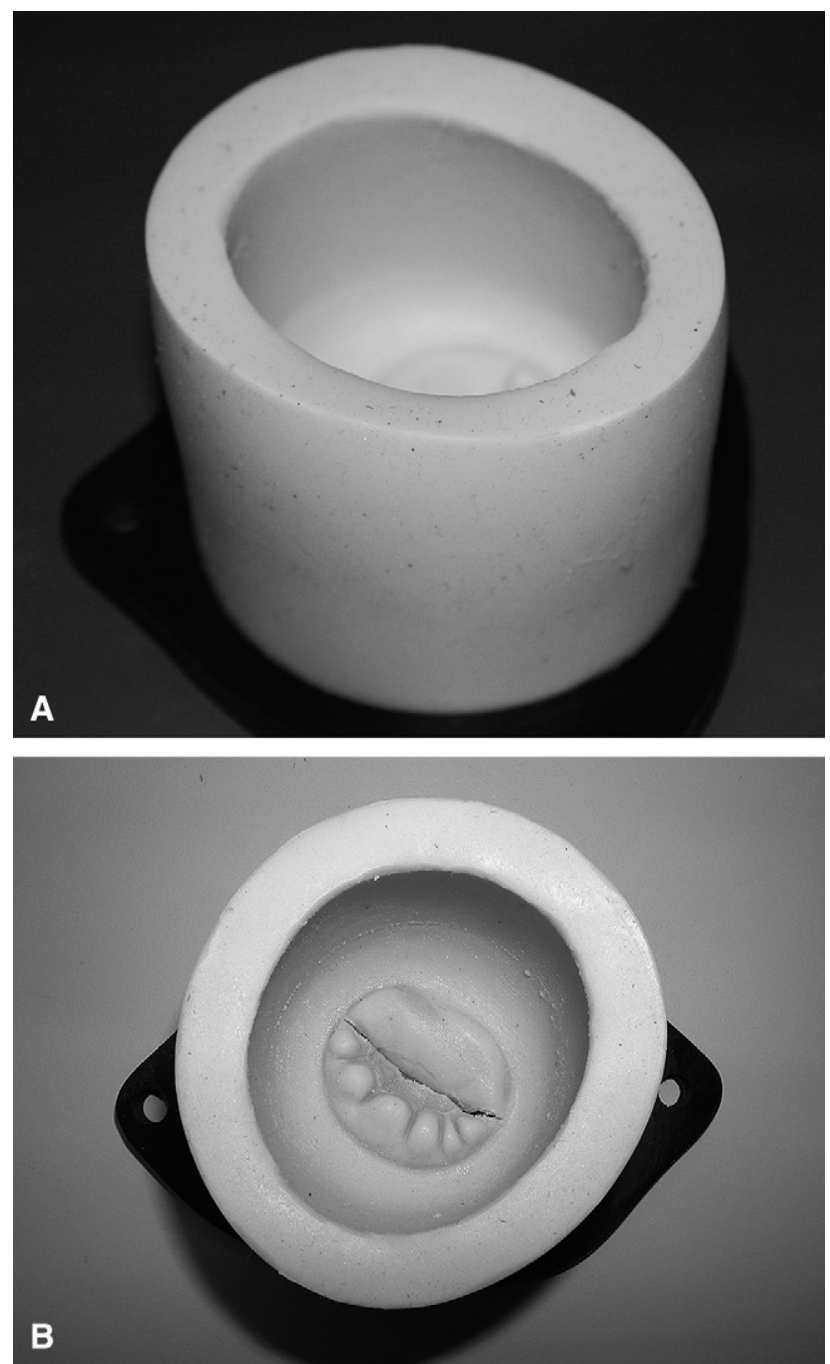

FIGURE 2. Plastic mitral valve model was used for home practice. A, Oblique view; B, top view.

by Gaba and associates. ${ }^{13}$ This statistic is a variant of Sav, which is based on the $\kappa$-like statistics of interrater agreement referenced to chance. Savr takes into account the ordinal nature of the scale and can accommodate 2 or more raters. For Savr, the by chance reference is computed on the assumption that raters would have an equal chance of using any of the rating scale elements in rating any particular item and subject. Correlation between home practice time and time to completion and composite score was obtained with a Pearson coefficient.

\section{RESULTS}

\section{Anastomosis Times}

Time to completion improved from $31 \pm 9$ minutes at the prefeedback session to $25 \pm 6$ minutes after 3 weeks of practice $(P=.03$; Figure 3$)$. Residents who required longer than 40 minutes at the initial session demonstrated marked improvement, whereas those who completed the initial exercise in less than 25 minutes showed modest to no improvement after practice. Improvement in time to completion was seen both in integrated residents (mean from $33 \pm 9$ minutes to $25 \pm 6$ minutes) and in traditional residents (mean from $29 \pm 11$ minutes to $23 \pm 6$ minutes).

\section{Technical Skills Assessment}

Performance assessment demonstrated an improvement in each of the components (Table 2). The technical scores varied from $2.4 \pm 0.6$ for needle angles to $3.0 \pm 0.5$ for depth of bite at the prefeedback session. After 3 weeks (postfeedback), performance improved in all components, with scores varying from $3.1 \pm 0.8$ for tissue handling to $3.6 \pm 0.8$ for suture management and tension. The degree of improvement appeared to be greatest in the identification of anterior annulus, needle angles, and suture management and tension. The lowest scores at the postfeedback session were in tissue handling $(3.1 \pm 0.8)$, needle angles $(3.2 \pm 0.5)$, and removing the needle from the annulus $(3.2 \pm 0.7)$. The interrater reliability for the performance rating scores was greater than 0.8 , demonstrating good reliability.

At the prefeedback session, 8 residents demonstrated a composite score less than 3 . At the postfeedback session, 3 residents failed to achieve a composite score of at least 3 , whereas 5 residents achieved a score of at least 3 in each component along with a composite score of at least 3 . There was no correlation between postgraduate year and time to completion improvement or overall score improvement $(-0.3$ and 0.1 , respectively). Performance of the integrated residents improved from a score of $2.6 \pm 0.6$ to $3.3 \pm 0.7$ $(P<.001)$, whereas performance of the traditional residents improved from $2.9 \pm 0.7$ to $3.5 \pm 0.6(P<.001)$. On average, residents practiced a mean of 3 hours (median, 2 hours; range, 0-10 hours) after reviewing the video feedback; practice time showed no to low correlation with improvement in time to completion or composite score (Pearson coefficients of 0.4 and -0.3 , respectively). In this small sample, the composite scores of first-year integrated and traditional residents were lower than those of senior level residents; comparatively, the third-year integrated residents demonstrated good technical proficiency (Figure 4).

\section{DISCUSSION}

In this study, time to completion and resident performance in mitral annuloplasty were improved by means of simulation and skills training with a period of practice and formative feedback. According to a global rating scale, both integrated and traditional residents showed improvement in the technical skills components, with composite scores of first-year integrated and traditional residents being lower than those of senior level residents; comparatively, third-year integrated residents demonstrated good technical proficiency. By providing the basis to develop an overall score, an important implication is that a "passing" grade 
TABLE 1. Components of performance rating scale

\begin{tabular}{|c|c|c|c|c|c|c|}
\hline \multirow{2}{*}{$\frac{\text { Component }}{1}$} & \multicolumn{2}{|l|}{ Description } & \multicolumn{4}{|c|}{ Rating } \\
\hline & $\begin{array}{l}\text { Identify posterior mitral annulus (demonstrate annulus, decussation or junction } \\
\text { of leaflet and atrial wall, for suture placement) }\end{array}$ & 1 & 2 & 3 & 4 & 5 \\
\hline 2 & $\begin{array}{l}\text { Identify anterior mitral annulus (demonstrate annulus, junction of leaflet } \\
\text { and fibroskeleton, for suture placement) }\end{array}$ & 1 & 2 & 3 & 4 & 5 \\
\hline 3 & $\begin{array}{l}\text { Needle angles (proper angle to permit needle point to puncture orthogonal to tissue } \\
\text { plane; consider depth of field, limits of access, and space constraints) }\end{array}$ & 1 & 2 & 3 & 4 & 5 \\
\hline 4 & Needle removal from annulus (follow curve of needle to minimize tissue trauma) & 1 & 2 & 3 & 4 & 5 \\
\hline 5 & Tissue handling (gentle manipulation without excessive tension and tissue trauma) & 1 & 2 & 3 & 4 & 5 \\
\hline 6 & $\begin{array}{l}\text { Depth of bite (proper depth of entry and exit points; proper and consistent depth } \\
\text { of needle and suture) }\end{array}$ & 1 & 2 & 3 & 4 & 5 \\
\hline 7 & $\begin{array}{l}\text { Suture advance along annulus (proper distance of suture travel in annulus, not } \\
\text { too small or too large) }\end{array}$ & 1 & 2 & 3 & 4 & 5 \\
\hline 8 & $\begin{array}{l}\text { Spacing between sutures (even spacing; consistent distance from previous bite, } \\
\text { not too close or too far) }\end{array}$ & 1 & 2 & 3 & 4 & 5 \\
\hline 9 & $\begin{array}{l}\text { Situating mitral ring (proper orientation relative to the annulus; proper suture } \\
\text { placement from edge; proper suture spacing) }\end{array}$ & 1 & 2 & 3 & 4 & 5 \\
\hline 10 & $\begin{array}{l}\text { Knot tying (adequate tension, facility; follow for finger and hand to secure } \\
\text { knots, not too loose or too tight) }\end{array}$ & 1 & 2 & 3 & 4 & 5 \\
\hline 11 & $\begin{array}{l}\text { Suture management and tension (avoid entanglement; use tension } \\
\text { and traction to assist exposure) }\end{array}$ & 1 & 2 & 3 & 4 & 5 \\
\hline
\end{tabular}

Definitions: 5, Excellent, able to accomplish goal without hesitation, showing excellent progress and flow. 4, Good, able to accomplish goal deliberately, with minimal hesitation, showing good progress and flow. 3, Average, able to accomplish goal with hesitation, discontinuous progress and flow. 2, Below average, able to partially accomplish goal with hesitation. 1, Poor, unable to accomplish goal; marked hesitation. Adapted from Objective Structured Assessment of Technical Skills. ${ }^{11,12}$

(eg, 3 out of 5 points) can be established for proficiencybased advancement.

With changes in residency training, the number of cases performed by cardiac surgical trainees has been lower during each year of training after implementation of work-hour restrictions, with an average of 460 total cases performed during the 1999 to 2002 interval compared with 337 cases during the 2003 to 2007 time interval. ${ }^{14}$ Also inherent in the transition from a traditional general surgery-based training paradigm to an integrated 6-year cardiothoracic surgical residency is the elimination of complex general surgical cases. Thus simulation-based skills training in this and previous studies has been proposed as an approach to enhance resident performance in cardiothoracic surgery. ${ }^{4-10}$ By focusing on components of surgical technique by using partial-task trainers and practice outside

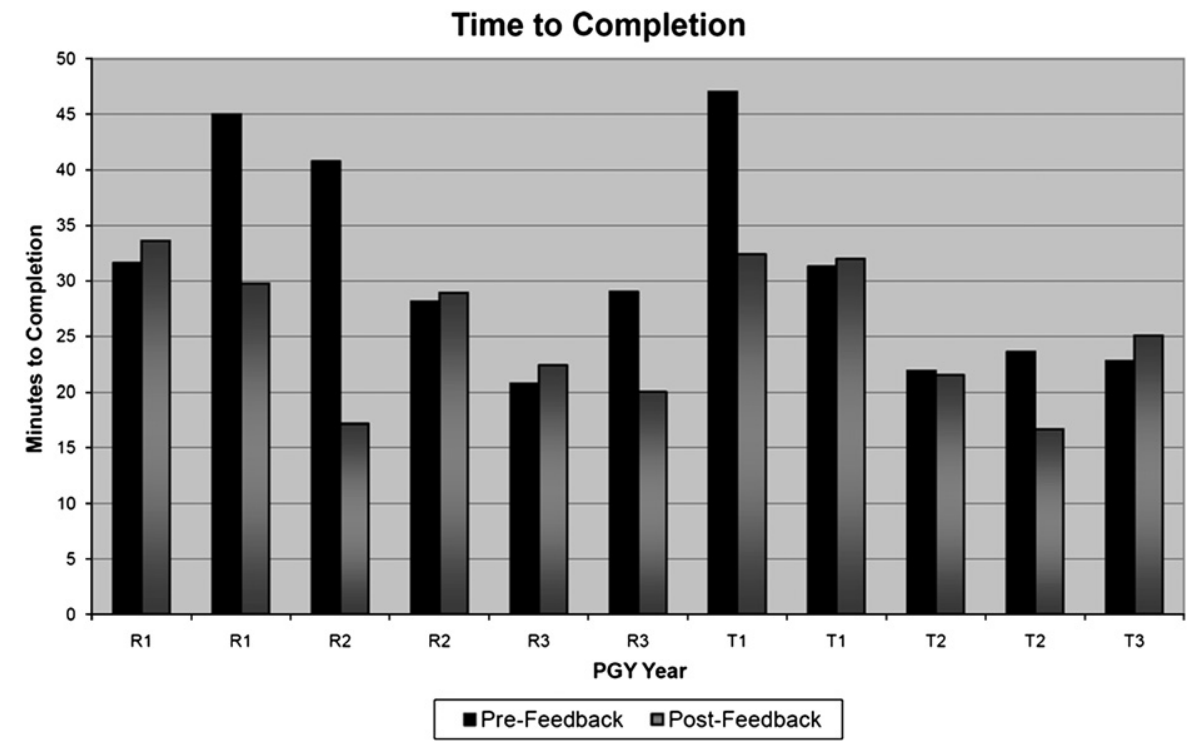

FIGURE 3. Times to completion before and after feedback for each resident with porcine mitral valve model. Integrated residents are designated by year out of medical school $(P G Y)$ as $R 1, R 2$, or $R 3$. Traditional residents are designated by year in cardiothoracic surgery residency as $T 1, T 2$, or $T 3$. 
TABLE 2. Mean performance rating scores comparing prefeedback and postfeedback sessions.

\begin{tabular}{|c|c|c|c|c|c|c|}
\hline \multirow[b]{2}{*}{ Technical component } & \multicolumn{2}{|c|}{ Prefeedback score } & \multicolumn{2}{|c|}{ Postfeedback score } & \multirow[b]{2}{*}{$P$ value } & \multirow[b]{2}{*}{ Difference $(\%)$} \\
\hline & Mean \pm SD & Range & Mean \pm SD & Range & & \\
\hline Identify posterior annulus & $2.7 \pm 0.8$ & $1-4$ & $3.4 \pm 0.6$ & $2-5$ & $<0.01$ & 27 \\
\hline Identify anterior annulus & $2.7 \pm 0.7$ & $1-4$ & $3.5 \pm 0.7$ & $2-5$ & $<0.01$ & 31 \\
\hline Needle angles & $2.4 \pm 0.6$ & $1-4$ & $3.2 \pm 0.5$ & $2-4$ & $<0.01$ & 31 \\
\hline Needle removal from annulus & $2.7 \pm 0.6$ & $2-4$ & $3.2 \pm 0.7$ & $2-4$ & $<0.01$ & 19 \\
\hline Tissue handling & $2.6 \pm 0.8$ & $1-4$ & $3.1 \pm 0.8$ & $2-5$ & $<0.01$ & 20 \\
\hline Depth of bite & $3.0 \pm 0.5$ & $2-4$ & $3.5 \pm 0.5$ & $3-4$ & 0.01 & 15 \\
\hline Suture advance along annulus & $2.8 \pm 0.6$ & $2-4$ & $3.5 \pm 0.8$ & $2-5$ & $<0.01$ & 28. \\
\hline Spacing between sutures & $2.9 \pm 0.7$ & $2-4$ & $3.5 \pm 0.7$ & $2-5$ & $<0.01$ & 20 \\
\hline Situating mitral ring & $2.7 \pm 0.9$ & $1-4$ & $3.4 \pm 0.8$ & $2-5$ & $<0.01$ & 28 \\
\hline Knot tying & $2.9 \pm 0.9$ & $1-4$ & $3.4 \pm 0.7$ & $2-5$ & $<0.01$ & 17 \\
\hline Suture management and tension & $2.7 \pm 1.0$ & $1-4$ & $3.6 \pm 0.8$ & $2-5$ & $<0.01$ & 31 \\
\hline
\end{tabular}

the operating room, residents can improve their basic technical skills in a graduated fashion and thus maximize their clinical experience. ${ }^{4-6}$

Mitral valve surgery is a complex procedure, requiring not only technical expertise but both extensive knowledge of anatomy and pathophysiology and sound intraoperative judgment. The focus of this study was directed toward the technical aspect of the annular suture placement and seating the annuloplasty ring. Although this focus is limited in the overall scope of mitral valve surgery, we propose that such technical skills must be mastered before any attempts are made at mitral valve surgery in the clinical setting. By acquiring these basic skills, the resident can focus on the cognitive and procedural components of mitral valve surgery in the operating room, such as attaining adequate exposure, assessing the pathology, and determining the appropriate approach and repair techniques. In this study, integrated residents overall (R1-R3) improved their postfeedback performance to a level that exceeded the scores of first-year traditional residents (T1) at the prefeedback session. This finding can be attributed to earlier exposure to and focus on cardiac surgical procedures in the integrated training program. Although these integrated residents had not previously performed mitral valve surgery in the clinical setting, some had participated in relevant "wet lab" experiences (R2 and R3 more than T1) or in previous research involving large animal surgery; importantly, they had served as a second assistant in many cardiac surgical procedures.

Despite the emphasis on home practice and deliberate practice, what is troubling is that many residents do not fully appreciate the importance of such practice in skill acquisition, as evidenced by a mean practice time of 3 hours during 2 weeks in this study. Because home practice is self-reported, its intensity and thus its impact are difficult

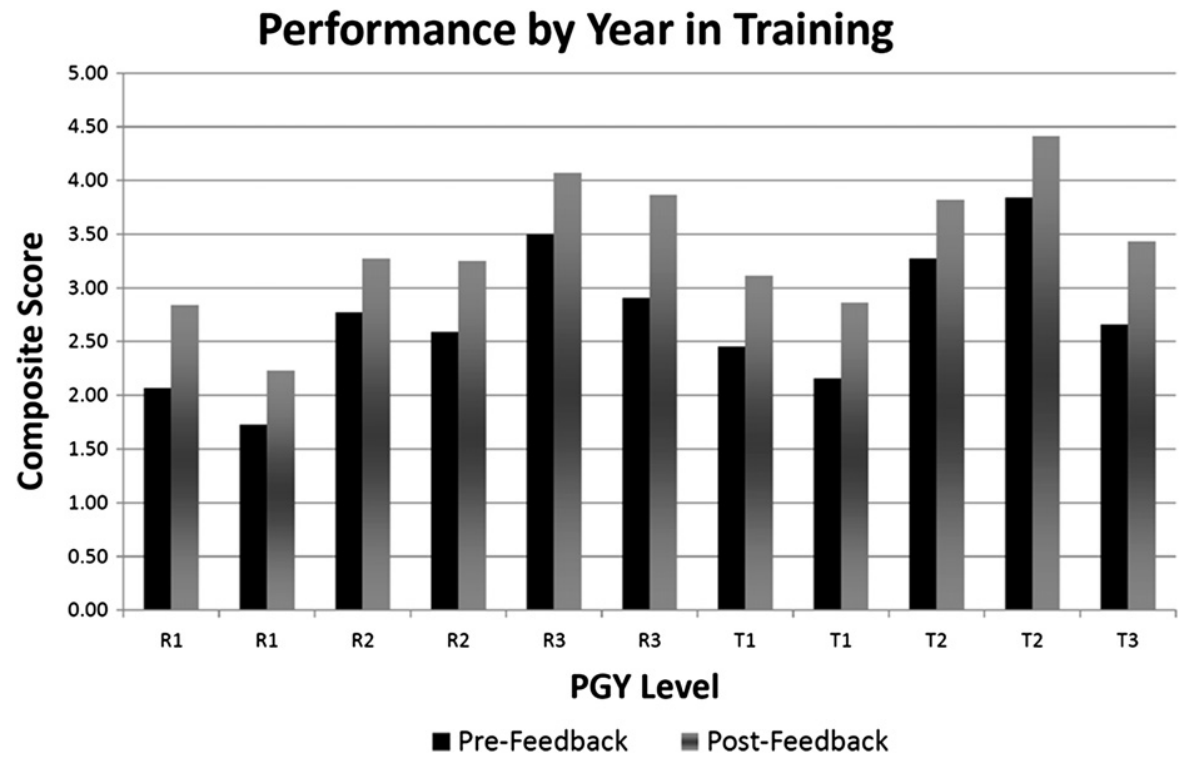

FIGURE 4. Composite score averaging each component for each resident. Integrated residents are designated by year out of medical school (PGY) as $R 1$, $R 2$, or $R 3$. Traditional residents are designated by year in cardiothoracic surgery residency as $T 1, T 2$, or $T 3$. 
to compare among trainees; nonetheless, it is imperative that the concept of deliberate practice be instilled in all residents, especially in view of work-hour restrictions and changes in residency training, with fewer open surgical cases in general surgical rotations. ${ }^{4-6,15,16}$ On the basis of evidence from other domains of expertise and expert performance, it is critically important to have teaching or "coaching" in the simulation laboratory by a skilled surgical educator, so that formative feedback and definition of areas of weakness requiring further practice or remediation can be carried out. ${ }^{15}$ This process could be similar to other domains (eg, music and sports), in which such coaching and feedback may take no more than a few hours a week. For the resident to improve his or her technical skills, defined practice periods at home and in a simulation laboratory are thus critically necessary.

\section{Limitations}

Mitral valve and subvalvular structures in the porcine model are not fully representative of the human heart, but the porcine model does provide good tactile feedback and realistic anatomic landmarks. Another limitation is that the silicone-based mitral valve model is of moderate rather than high fidelity. Practice on such a model may account for the fact that there was low to no correlation with improvement on the porcine heart model. As noted, the plastic model does provide some of the components of mitral valve surgery that we consider important; however, development of more realistic and challenging models and simulators is necessary. Simulation-based learning and skills training in cardiac surgery may not transfer to the operative setting with high-stakes, open surgical procedures; transferability will require definition of the tasks that can be simulated and that can be accurately assessed in the operating room without negatively affecting patient safety. The 11 components used in the rating scale were determined to represent surgical skill at a single institution; other components not studied may be deemed equally or more important by others. The composite score may not truly represent the resident's performance, because each component comprising the overall score is given equal weight; the intent of the composite score was to present an estimate of the overall performance to provide a means for comparison in this study. To use a composite score or grade for summative assessment, it will be necessary to establish consensus among subject matter experts and to weigh each component of the evaluation. It is recognized that the relatively small number of participants limits the extent to which comparisons can be made between integrated and traditionally trained residents. Also, because this cohort of residents was limited to a single institution, a multi-institutional study is necessary to define the role for cardiac surgical simulation in the development of a technical skills curriculum and assessment. Future work will investigate the use of more realistic simulators and a strategy of mandatory practice with feedback (defined length and intensity of practice), which may demonstrate a correlation between degree of practice and improved performance.

This study suggests that introducing simulation exercises in mitral valve surgery provides an effective means of enhancing the resident's mastery of skills. By developing a standardized method of assessment based on these 11 components, we have established a technique that permits an individualized approach to remediation and practice. On the basis of our comparison of data between integrated and traditional residents, this type of strategy with simulation-based skills learning may offer a solution to the some of the limitations of training residents in the current era.

We gratefully acknowledge David Gaba, MD, for his assistance with the statistical analysis.

\section{References}

1. Suri RM, Schaff HV, Dearani JA, Sundt TM 3rd, Daly RC, Mullany CJ, et al. Survival advantage and improved durability of mitral repair for leaflet prolapse subsets in the current era. Ann Thorac Surg. 2006;82:819-26.

2. Gammie JS, Sheng S, Griffith BP, Peterson ED, Rankin JS, O'Brien SM, et al. Trends in mitral valve surgery in the United States: results from the Society of Thoracic Surgeons Adult Cardiac Surgery Database. Ann Thorac Surg. 2009; 87:1431-9.

3. Accreditation Council for Graduate Medical Education [Internet]. Chicago: The Council; c2000-2010 [updated 2006 Mar 31]. RRC-TS and ABTS Minimum Case Requirements [1 screen]. Available from: http://www.acgme.org/ acWebsite/RRC_460/460_caseVolReq7_1_07.pdf

4. Fann JI, Caffarelli AD, Georgette G, Howard SK, Gaba DM, Youngblood P, et al. Improvement in coronary anastomosis with cardiac surgery simulation. J Thorac Cardiovasc Surg. 2008;136:1486-91.

5. Fann JI, Calhoon JH, Carpenter AJ, Merrill WH, Brown JW, Poston RS, et al. Simulation in coronary artery anastomosis early in cardiothoracic surgical residency training: the Boot Camp experience. J Thorac Cardiovasc Surg. 2010;139: 1275-81.

6. Hicks GL Jr, Gangemi J, Angona RE Jr, Ramphal PS, Feins RH, Fann JI. Cardiopulmonary bypass simulation at the Boot Camp. J Thorac Cardiovasc Surg. Epub 2010 May 6

7. Carpenter AJ, Yang SC, Uhlig PN, Colson YL. Envisioning simulation in the future of thoracic surgical education. J Thorac Cardiovasc Surg. 2008;135:477-84.

8. Hicks GL Jr, Brown JW, Calhoon JH, Merrill WH. You never know unless you try. J Thorac Cardiovasc Surg. 2008;136:814-5.

9. Feins RH. Expert commentary: Cardiothoracic surgical simulation. $J$ Thorac Cardiovasc Surg. 2008;135:485-6.

10. Ramphal PS, Coore DN, Craven MP, Forbes NF, Newman SM, Coye AA, et al. A high fidelity tissue-based cardiac surgical simulator. Eur J Cardiothorac Surg. 2005;27:910-6.

11. Reznick R, Regehr G, MacRae H, Martin J, McCulloch W. Testing technical skill via an innovative "bench station" examination. Am J Surg. 1997;173:226-30.

12. Martin JA, Regehr G, Reznick R, MacRae H, Murnaghan J, Hutchison C, et al. Objective structured assessment of technical skill (OSATS) for surgical residents. Br J Surg. 1997;84:273-8.

13. Gaba DM, Howard SK, Flanagan B, Smith BE, Fish KJ, Botney R. Assessment of clinical performance during simulated crises using both technical and behavioral ratings. Anesthesiology. 1998;89:8-18.

14. Connors RC, Doty JR, Bull DA, May HT, Fullerton DA, Robbins RC. Effect of work-hour restriction on operative experience in cardiothoracic surgical residency training. J Thorac Cardiovasc Surg. 2009;137:710-3.

15. Ericsson KA, Krampe RT, Tesch-Romer C. The role of deliberate practice in the acquisition of expert performance. Psychol Rev. 1993;100:363-406.

16. Reznick RK, MacRae H. Teaching surgical skills—changes in the wind. N Engl J Med. 2006;355:2664-9. 